\title{
Curricular improvements for entrepreneurial education
}

\author{
Simona VASILACHE \\ The Bucharest University of Economic Studies, Bucharest, Romania \\ Johana RÎNCIOG \\ The Bucharest University of Economic Studies, Bucharest, Romania \\ johana.rinciog@gmail.com
}

\begin{abstract}
Our paper aims at investigating the most adequate methods for developing effective educational tools in entrepreneurial education. Entrepreneurship education should take place during the entire life of an entrepreneur, but the basic knowledge and skills related to this field are acquired starting from the elementary school, and improved during all the educational levels. Through entrepreneurship education, policymakers aim to prepare young people for succeeding on the entrepreneurial path. However, there are few scientific papers that aimed at discussing the available educational tools in Romania which play a role in forming entrepreneurs. Starting from the identified educational needs of young Romanian people under 35, including entrepreneurs and students, which were surveyed based on a questionnaire, we advance several key improvement areas for Romanian business curricula, and suggest critical paths to obtain desired results. The recommendations that we deliver through this paper are based on respondents' opinions regarding their preference for certain aspects related to educational tools used in entrepreneurial education: learning materials used in universities in order to create an entrepreneurial mindset, the use of learning materials outside of the university curricula, and entrepreneurial skills that should be developed during school. A comparative perspective, examining curricular specificities in most entrepreneurial cultures of Europe, based on information obtained from Entrepreneurship Eurobarometer and Doing Business Indicators, is also included in our study. The main limitations, which arise from the subjective perspective of young entrepreneurs, as well as from the reduced sample volume, are thus corrected. The conclusions of our analysis provide a valuable starting point for educational policies promoting entrepreneurial skills enhancement in the Romanian business students' population.
\end{abstract}

Keywords: entrepreneurship, entrepreneurial education, university learning tools.

\section{Introduction}

Entrepreneurship is considered as one of the major contributing factors to economic development, reason for which this topic receives an increasing attention from researchers and policymakers. Policymakers in developing countries created a favorable context for people to choose the entrepreneurial path, because they understood the positive influence of entrepreneurs over the modern society. However, in less developed countries, policymakers begin only now to understand the importance of entrepreneurship, especially in job creation, reason for which they started to perform interventions aimed at creating an entrepreneurial culture (Premand et al, 2016). One example in this sense may refer to the efforts of policymakers for improving entrepreneurship education, in order to help young people to acquire the needed entrepreneurial skills and to create jobs for others.

In EU, small and medium sized enterprises (SMEs) represent almost $90 \%$ of the total number of businesses. Except for their contribution to an increasing degree 
of innovation and social integration, SMEs in EU provide jobs for two-thirds of the people who need a place to work (Hobikoglu and Sanli, 2015). Thus, the institutions of EU have strong reasons to encourage young people to pursue the entrepreneurial path, especially in the context where the percentage of people interested in this career is significantly lower than in US or China (30\% versus $50 \%$ ).

There is a wide variety of measures implemented by Member States with the purpose to facilitate a more friendly business environment for people interested in starting their own venture. Out of these, we want to mention the following: creating a favorable legal and fiscal framework for SMEs to reach new markets within or outside $\mathrm{EU}$, facilitating the access to finance, increasing accessibility to information, or improving entrepreneurship education (Vilcov and Dimitrescu, 2015).

Starting from these statements, we decided to dedicate the current paper for discussing the actual measures implemented by policymakers for providing entrepreneurship education, and to formulate recommendations for possible improvements related to this topic. The premise from which we started this research is based on the belief that lays at the basis of European Commission's efforts for fostering entrepreneurship through education: entrepreneurship is a skill that can be improved through the development of an entrepreneurial mindset. Otherwise stated, our society needs to pay attention to the curricula of entrepreneurship education from primary school to university, and further on.

\section{Theoretical framework}

\section{Entrepreneurship education}

Entrepreneurship education gained a significant interest from governments, once policymakers understood the need for encouraging more people to follow this career path. Over the time, this idea was supported by many researchers. For example, Lim et al (2010) sustained that entrepreneurial activity is enhanced by a favorable environment where different institutions bring their contribution in various ways: state incentives, a favorable legal system, a supportive infrastructure, economic freedom, and so on. However, researchers as Walter et al (2013), underline the idea that entrepreneurship education may improve people's intention for choosing to become entrepreneurs. This perspective provides our society with a new perception over the available opportunities to encourage entrepreneurship.

According to Walter and Block (2016) entrepreneurship education consists of curricular and extra-curricular offerings through which individuals learn different aspects related to entrepreneurship, such as the following: identifying and taking advantage of business opportunities, stages for implementing a business idea, strategies for growing their ventures, management practices (Dima, 2009, Miron et al., 2009), and other topics related to entrepreneurship. That means to develop new patterns of thinking (Bratianu, 2007, 2009), and to implement them into the students' education.

Another perspective over the importance of entrepreneurship education is brought by Harms (2015). The author affirms that entrepreneurship education represents a way to increase the number of entrepreneurs by preparing students for self-employment in a complex and uncertain market, and to help them develop their skills. 
Entrepreneurship education is defined on Entrepreneurship Euro barometer as a way to develop entrepreneurial skills, and to improve individuals' knowledge on this field in order to increase people's interest for self-employment. In EU, entrepreneurship education is provided according to the standards set by each Member State. However, the European Commission adopted a series of principles that should be practiced by all countries of EU such as the following: sharing of knowledge, practices and ideas between Member States (Hobikoglu and Sanli, 2015), accessibility to studies on market research, identification of new instruments for facilitating entrepreneurship education (Jansen et al, 2015), and development of projects where participants have the opportunity to develop an entrepreneurial mindset (Basci and Alkan, 2015).

The great attention placed on this topic enables us to identify various perspectives over entrepreneurship education. However, the scientific research concentrated on analyzing different aspects of this topic, are a proof that more and more universities invest effort and knowledge in educational programs that form young entrepreneurs prepared to face the challenges of the outside world. Consequently, young people have more opportunities to create their own jobs, to obtain a higher income than those offered by employers, or a proportional income with the amount of work performed, and to bring their contribution to the economic development of a country (Din et al, 2016).

\section{Entrepreneurship education practices at EU level}

Entrepreneurship education gained more importance over the time, leading to the creation and implementation of different programs aimed at improving this aspect for the society. In this sense, the European Commission compiled a plan for organizing the entrepreneurial knowledge transfer during different stages of education.

Regarding the primary education, the European Commission considers that learners should acquire knowledge regarding the benefits of entrepreneurship for society, they should be taught to use their creativity and spirit of initiative through encouraging their natural curiosity, and to increase their initiative and responsibility. In this sense, the practices available to educational institutions are the following: projects, case studies, games through which learners assume roles (such as pupils selling products), competitions where pupils are encouraged to come up with innovations for which they receive rewards, or visits to small and medium enterprises (Ruskovaara et al, 2015).

During the secondary education, the European Commission established that learners should be accustomed with the idea of self-employment as a career option (Vilcov and Dimitrescu, 2015). The entrepreneurship curricula should consist of practical projects and activities where students learn by doing, they develop selfconfidence and improve team work. However, the focus is not on subjects studied in school, but on programs requiring students to simulate all the steps for starting and running a venture.

Finally, in the case of higher education, the European Commission sustains that entrepreneurship education should be provided in all universities, regardless of subjects studied. At this level of education, all students should develop an entrepreneurial mindset in order to commercialize their ideas and innovations. The 
curricula should consist of entrepreneurship courses that teach students the steps for starting a business, growth strategies, and so on. Other practices that could be adopted at this level of education, are the following: the development of doctoral programs on entrepreneurship, case studies, business plans competitions, the creation of incubators in universities, and the formation of interdisciplinary teams of students that allow the sharing of knowledge (Jansen et al, 2015).

Even though these recommendations of European Commission seem ambitious, especially for certain less developed countries, Welsh et al (2016) sustains that entrepreneurship education is in a phase of transition, and in time, these measures will become possible. The author's observation is based on the idea that educational providers are subject to a series of changes regarding two aspects of entrepreneurship education: changes at the conceptual level (new methods for providing entrepreneurship education), and changes in the tools used for delivering entrepreneurship education (entrepreneurship networks, eLearning, etc.).

One first area refers to technology. The technology is perceived as an opportunity for entrepreneurship education because it enables flexible and individualized forms of education and training (Basci and Alkan, 2015). It should not be overseen the fact that the current generation is characterized as digital-born learners, meaning that educational facilities should collaborate with advanced educational providers in order to facilitate the access to the new technology.

A second area of improvement would be the creation of more partnerships between educational institutions and private sector, such as entrepreneurs, companies, consultants, and so on (Ruskovaara et al., 2015, Dima et al., 2016). Partnerships represent a context where students can develop their skills in a sustainable and innovative way because partners of private sector agree to sponsor schools' initiatives or to directly teach the students. In terms of partnerships aimed at fostering entrepreneurship education, EU pays a great attention to Knowledge Alliances, which stimulate the exchange of knowledge between educational institutions and enterprises (Jansen et al, 2015). In this way, the partnerships contribute to an increased degree of innovation, and to develop skills such as entrepreneurial skills, creative thinking or problem solving.

\section{Research design \\ Questionnaire}

As mentioned previously, in order to perform the research for this paper, the survey technique was applied and a questionnaire was developed.

The questionnaire was addressed to Romanian students from bachelor and master degree in the economics field, out of which a part of them are Business Administration students and students who started their own ventures. The questionnaires were applied in an online form, through email, and in physical form. The period of the survey application was December 2016 - January 2017. There were collected 50 questionnaires, out of which 44 were valid. The data collected through this survey was processed in Excel.

The two categories of respondents mentioned previously, were selected because it was considered that students who follow Business studies will own a business at a certain moment in their career, and those who are already 
entrepreneurs, have the required knowledge and experience to provide answers for our research questions. For the rest of respondents who do not fit in these categories, it was assumed that, as students in the economic field, they may be interested in gaining knowledge about entrepreneurship, and in starting their own business at a certain moment of their career.

The points covered in this survey aimed at revealing respondents' opinion regarding actual practices of entrepreneurship education, and suggestions for improving these practices, such that young people are prepared to face the new challenges of the business environment.

\section{Data analysis}

This part of the paper is dedicated to presenting a part of the observations obtained from the survey. As such, the main points that will be covered in the following lines relate to the following aspects: the importance of entrepreneurship studies in raising interest for this field, university factors that increase respondents' interest for entrepreneurship, entrepreneurial characteristics that should be developed through education, extracurricular activities for improving the entrepreneurship knowledge, and an assessment of respondents' intention to become entrepreneurs.

The first set of observations aim to highlight respondents' opinions regarding the importance of entrepreneurship studies in raising their interest to start a venture. The respondents were required to rate this aspect using a scale between 1 and 5, where 1 means not interested at all, and 5 means very interested. The results obtained were summarized in the following table.

Table 1: Business education rating

\begin{tabular}{|l|l|}
\hline Business education rating & \% of respondents \\
\hline 1 & $0 \%$ \\
\hline 2 & $5 \%$ \\
\hline 3 & $20 \%$ \\
\hline 4 & $45 \%$ \\
\hline 5 & $30 \%$ \\
\hline
\end{tabular}

Source: Authors' own research results.

The results obtained show that almost half of students considered that Business education is important in helping them to become entrepreneurs. For example, a third of respondents suggested that entrepreneurship education received in university has a very strong influence over their perception regarding the entrepreneurial path. These results might suggest that Business students look also for other ways to enhance their entrepreneurial motivation, which may be the following: learning from other entrepreneurs serving them as role models, dissatisfaction with the life as employee, being aware about their talents that they want to use in the service of people, and so on.

A second point covered in this survey refers to respondents' preference regarding different university factors that enhance their desire to become entrepreneurs. In this sense, several alternatives were made available to them: teachers, guest speakers, case-studies, materials watched/read during classes, student associations, colleagues, events, or the possibility to access European Funds through 
university programs. The results of data gathered for this question are presented in the following graphical illustration.

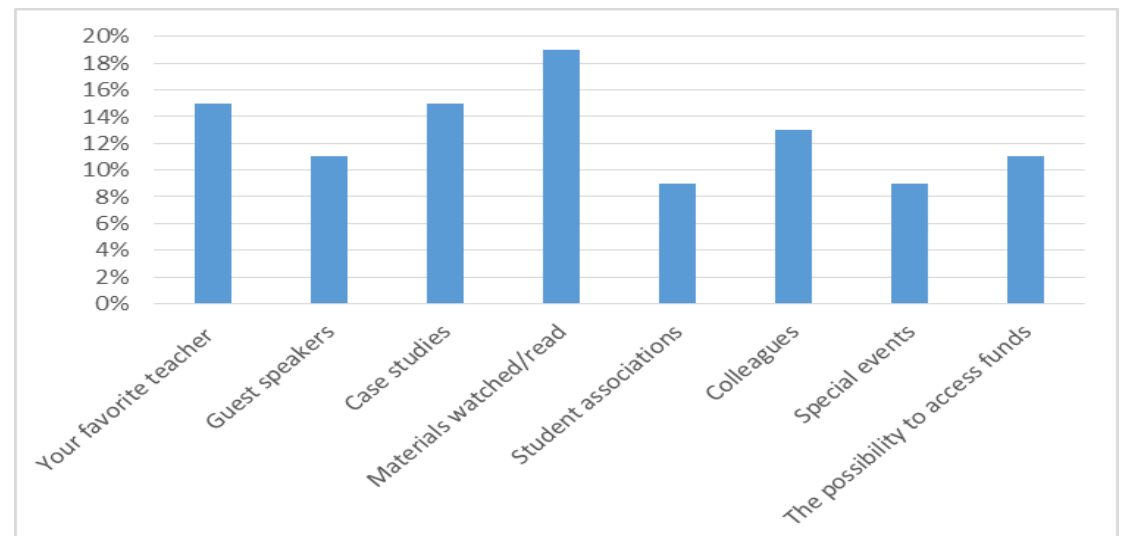

PICBE | 307

Figure 1: University factors changing students' perception on entrepreneurship

Source: Authors' own research results.

According to respondents' answers, it seems that the University tools having the highest impact on students' perspective on becoming entrepreneurs, are the following: materials watched/read during classes, experience of teachers, case studies, and colleagues with entrepreneurial experience, guest speakers and the possibility to access funds. These results indicate the importance of discussions and of the exchange of opinions, aspects that should be encouraged in universities. Allocating sufficient time for interactions with teachers, encouraging students who have experience in this field to share their knowledge, debating case studies, all of these could stir the curiosity of students for entrepreneurship. On the other side, students should prepare questions for those with more experience in entrepreneurship, because if they do not express their thoughts and doubts, they will not find answers and encouragement.

After identifying students' preference for teaching tools, the survey aimed at discovering those entrepreneurial characteristics that they should develop with the help of school. The weights recorded by each of the options presented, are shown in the following graphical illustration.

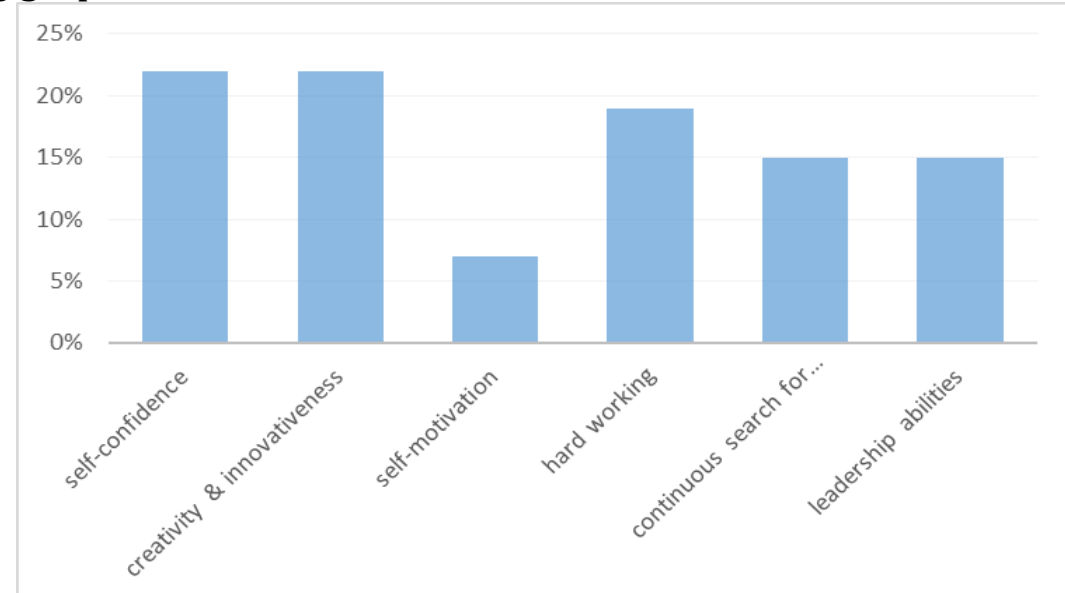

Figure 2. Students' perception over the needed entrepreneurial characteristics

Source: Authors' own research results 
As it can be seen, the most selected options were self-confidence, creativity and innovation. Other entrepreneurial characteristics for which a significant percentage was recorded, were the following: the discipline for becoming hard working, a continuous search for opportunities, and leadership abilities. Therefore, universities should adopt models and tools of entrepreneurship education, which help students to acquire these skills (Dima and Ghinea, 2016).

Respondents were also required to express their opinion regarding practices available outside the curricula of universities, which they perform for developing their knowledge about entrepreneurship. As such, the survey revealed that other practices of young people interested in expanding their entrepreneurship knowledge, are the following: reading articles in magazines, watching videos of successful businessmen, following entrepreneurs on social media, or participating at events dedicated to entrepreneurship where they have the opportunity to network.

Finally, the last aspect to be emphasized based on the survey refers to respondents' intention to follow the entrepreneurial path after completing the studies (Figure 3).

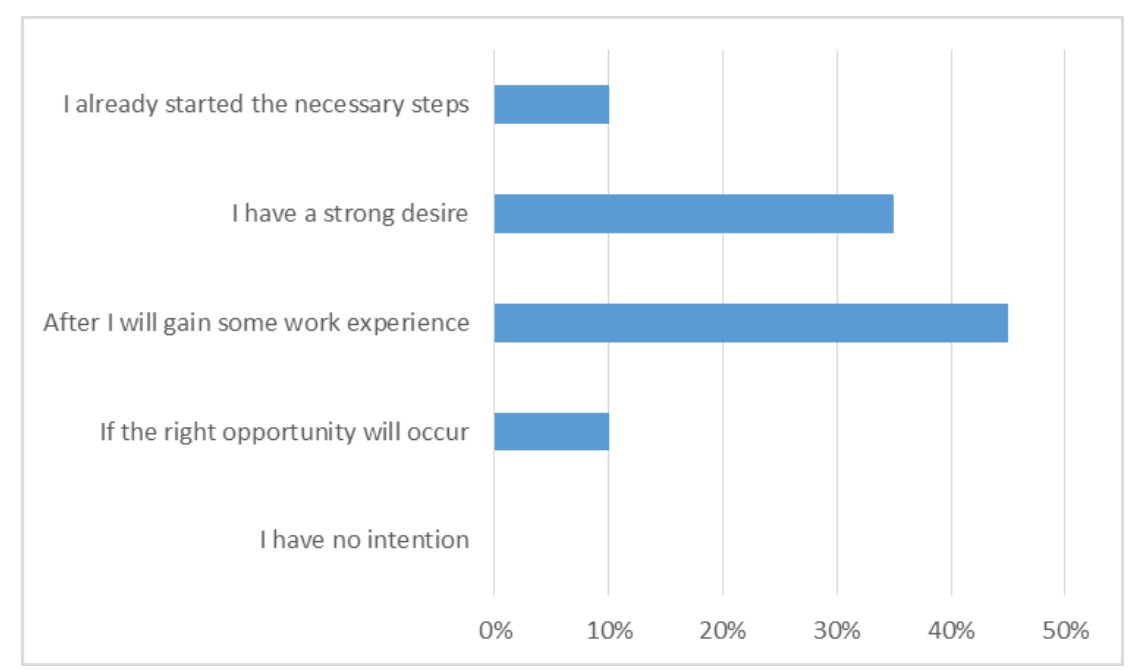

Figure 3: The students' intention to start a business after completing the studies Source: Authors' own research results

Approximately half of respondents stated that they intend to open a business after gaining some work experience. This may be due to the fact that they do not have the necessary knowledge to run an organization, to assume certain responsibilities, to deal with certain situations, or simply because they wait to gather more financial resources for starting their venture. However, a close percentage of respondents affirmed that they have a strong desire to start a venture.

Finally, the survey was aimed at finding respondents' recommendations regarding learning practices that should be used by students interested to become entrepreneurs. The results showed that networking and attending conferences dedicated to entrepreneurship, are the most preferred learning practices.

\section{Discussion}


Young people are a valuable asset for a country because they contribute to the economic development through the work they perform (Din et al, 2016). In these modern times, governments place more and more attention on the level of education of young people because the public and private sectors are more and more demanding regarding this aspect. In the current research we decided to treat the case of entrepreneurship education at the level of EU and with a focus on the case of Romania. The analysis of entrepreneurial education curricula in EU and the analysis of the survey revealed certain common points between practices from Romania and those of other Member States and, in the same time, several differences.

For example, we noticed common practices in universities, such as the use of case studies, materials about entrepreneurship, competitions between students, programs organized by universities, and so on. One important practice of entrepreneurship education that shows the alignment of Romanian universities with EU standards, refers to partnerships with private sector. These partnerships may refer to sponsorships of competitions between students, agreements of business persons to be guest speakers, internships in companies, and other forms of collaborations. Our research highlights the satisfaction of students with these practices, but a large part of respondents suggested that the knowledge gained during university does not compensate their lack of experience, which prevents them from becoming entrepreneurs after finishing the studies.

At this point of our research it is the moment to consider options for improving the entrepreneurship education in Romania. The first step that should be performed is to provide entrepreneurship education starting from primary education. Thus, during the primary and secondary education learners should acknowledge the benefits of entrepreneurship, and they should perform different activities for increasing selfconfidence, a competitive spirit and a desire to learn by doing. Perhaps, if schools would organize games or volunteering activities where young people are encouraged to assume roles, these pupils would gain self-confidence and experience in negotiation, persuasion, team work, etc.

A second step would be to introduce entrepreneurship courses in all universities. As considered by European Commission, students from all fields of study should be aware about the possibility to commercialize their ideas or innovations.

A final recommendation from our part refers as well to entrepreneurship education provided in universities. Based on observations obtained from the survey, we consider that students should be presented with more opportunities for enriching their entrepreneurial knowledge and experience. For example, students should be encouraged to read business books, to watch videos of successful businessmen, to attend events dedicated to entrepreneurs, to read on a regular basis articles on entrepreneurship, and so on.

As mentioned earlier in this paper, the way for improving entrepreneurship education is to look at other educational systems that are successful in this regard, and to find solutions for adopting their practices. However, education is not only the output of efforts performed by educational institutions, but also the output of efforts performed by individuals. From here it results the need to form an entrepreneurial mindset to young people since primary education. Once this people are used with the 
concept, they will show openness and willingness to develop entrepreneurial skills, and to consider pursuing this path.

\section{Conclusion}

As a conclusion of this paper, we affirm that our research demonstrates an increasing interest for entrepreneurship both in Romania and at EU level. Of course, the proposal of European Commission is not applied at this moment in Romania, since entrepreneurship education is provided mainly during the higher education, and especially for economics and business students. Therefore, there is enough place for improvements, and a high need for our society to develop young people willing to become entrepreneurs.

The research performed in this paper has a series of limitations, such as the following: the survey was applied only to higher education, or the questionnaire did not take into consideration an analysis of respondents' opinion regarding students' competitions, partnerships between university and private sector, and other activities that allow student to learn by doing. However, the information obtained at this moment demonstrates that progress is achieved in Romanian educational institutions, which contribute to forming more young people with an entrepreneurial mindset.

This paper brings a valuable contribution to the research on entrepreneurship education by offering some guidelines regarding its future direction. More exactly, the current study comes with a series of proposals related to university factors that may increase respondents' interest for entrepreneurship, entrepreneurial skills to be developed in school, and extracurricular activities for improving knowledge in this field. A continuous research on this topic would help education providers to become aware about the expectations of young people in this sense, and to find more effective ways for improving the entrepreneurial mindset of young people.

\section{References}

Basci, E. and Alkan, R., (2015). Entrepreneurship education at universities: suggestion for a model using financial support. Procedia - Social and Behavioral Sciences. 195, 856-861.

Bratianu, C. (2007). Thinking patterns and knowledge dynamics. In D. Remenyi (ed.). Proceedings of the $8^{\text {th }}$ European Conference on Knowledge Management (pp. 152-156), Consorci escolar Industrial, Barcelona, Spain, 6-7 September 2007. Bratianu, C. (2009). The frontier of linearity in the intellectual capital metaphor. In C. Stam (Ed.). Proceedings of the European Conference on Intellectual Capital (pp. 97-103), Inholland University of Applied Sciences, Haarlem, The Netherlands, 28-29 April 2009.

Dima, A.M. (2009). Operational risk assessment tools for quality management in banking services. Amfiteatru economic, 11(26), 364-372.

Dima, A. M., \& Ghinea, V. (2016, November). A Model of Academic Leadership. In European Conference on Management, Leadership \& Governance (p. 61). Academic Conferences International Limited. 
Dima, A. M., Hadad, S., \& Cantaragiu, R. (2016). A conceptual analysis of businessuniversity knowledge transfers in the energy field. ENERGY, CLIMATE CHANGE AND SUSTAINABILITY, 201-207.

Din, B., Anuar, A. and Usman, M., (2016). The effectiveness of the entrepreneurship education program in upgrading entrepreneurial skills among public university students. Procedia - Social and Behavioral Sciences. 224, 117-123.

Harms, R., (2015). Self-regulated learning, team learning and project performance in entrepreneurship education: learning in a lean start-up environment. Technological Forecasting \& Social Change. 100, 21-28.

Hobikoglu, E. and Sanli, B., (2015). Comparative analysis in the frame of business establishment criteria and entrepreneurship education from the viewpoint of economy policies supported by innovative entrepreneurship. Procedia - Social and Behavioral Sciences. 195, 1156-1165.

Jansen, S., Zande, T., Brinkkemper, S., Stam, E. and Varma, V., (2015). How education, stimulation and incubation encourage student entrepreneurship: observations from MIT, IIIT, and Utrecht University. The International Journal of Management Education. 13, 170-181.

Lim, D., Morse, E., Mitchell, R. and Seawright, K., (2010). Institutional environment and entrepreneurial cognitions: a comparative business systems perspective. Entrepreneurship: Theory and Practice. 34, 491-516.

Miron D., Dima A.M. and Vasilache S.N. (2009), Indexes of regional economic growth in post-accession Romania, Romanian Journal of Economic Forecasting, 11(3), 138-152.

Premand, P., Brodmann, S., Almeida, R., Grun, R. and Barouni, M., (2016). Entrepreneurship education and entry into self-employment among university graduates. World Development. 77, 311-327.

Ruskovaara, E., Pihkala, T., Leino, J. and Jarvinen, M., (2015). Broadening the resource base for entrepreneurship education through teachers' networking activities. Teaching and Teacher Education. 47, 62-70.

Vilcov, N. and Dimitrescu, M., (2015). Management of entrepreneurship education: a challenge for a performant educational system in Romania. Procedia - Social and Behavioral Sciences. 203, 173-179.

Walter, S. and Block, J., (2016). Outcomes of entrepreneurship education: an institutional perspective. Journal of Business Venturing. 31, 216-233.

Walter, S., Parboteeah, K. and Walter, A., (2013). University departments and selfemployment intentions of business students: a cross level analysis. Entrepreneurship: Theory \& Practice. 37, 175-200.

Welsh, D., Tullar, W. and Nemati, H., (2016). Entrepreneurship education: process, method or both. Journal of Innovation and Knowledge. 1, 125-132. 